for hard reading but, when translated, it explains the fundamental reason why the ethanol subsidies for which the rich world's farmers lobby will do nothing for energy supply - unlike some of the other biomass energy routes.

Wind is perhaps the most interesting renewable: "generating $20 \%$ of US electricity demand would require less than $1 \%$ of land in the contiguous US, of which less than $5 \%$ would actually be taken up by the turbines themselves." The constraints will be those of systems and time, not natural resources. This is particularly true of the hydrogen economy, where Smil offers well-judged cautions and questions about current enthusiasms.

In his concluding chapter on possible futures, Smil emphasizes the complexities and timescales of change, which leads him to be generally conservative in the short term but with a broad long-term vision of what might be possible. This is true for both supply and demand: despite the book's emphasis on energy efficiency, Smil dismisses the fantasies of tenfold improvements being accomplished within a single generation.

Smil has the wisdom to frame the really big issues. He rejects the wishful thinking that the problems of energy are not real and the false hopes that they will go away or solve themselves. Truth matters, and is found neither in the specific scare stories or techno-optimism of many environmentally oriented writers, nor in the growth-blinded pronouncements of economic modellers and forecasters.

Yet Smil derives two big questions from the fundamentals of each of these world concerns: "If our actions were guided by the two greatest concerns a sapient terrestrial civilisation can have - for the integrity of the biosphere and for the dignity of human life — then it would be inescapable to ask the two most fascinating questions in energy studies: what is the maximum global TPES [primary energy supply] compatible with the perpetuation of vital biospheric services, and what is the minimum per capita energy use needed for a decent quality of life?" Smil says these questions are rarely asked, not only because they are extraordinarily difficult to answer, but because they demand clear moral commitment. Charting the energy horizons of environment and inequality, his conclusion boils down to Ghandi's famous dictum: the world has enough for everyone's need, but not enough for everyone's greed.

The policy implications outlined by Smil are not simple. How to promote efficiency and innovation without increasing consumption? How to reduce energy use among those who already overconsume fuel and boost it among those who don't? "When facing so many uncertainties, we should pursue any effective means that bring us closer to those goals," with "no categorical exclusion of certain ingredients (such as nuclear or big dams), no inflexible insistence on what is best."
This book should change the map by which we navigate the new energy century. In its intellectual content it is a great book, standing head and shoulders above most integrated writings on energy and environment. The complex, dense prose and tendency for rigorously balanced views may inhibit readers, but the book's underlying themes could and should prove the book's legacy. For example, Smil discusses the essential unpredictability and openness of energy futures, and provides a comprehensive critique of the notion that incessantly rising energy demand in industrialized countries is associated with increasing welfare though doing anything about it will not be easy. The book has gone straight to the top of my reading recommendations for my students. And for the serious technical analyst of energy systems, there is nothing better. Michael Grubb is professor of Climate Change and Energy Policy, Imperial College London, Exhibition Road, London SW7 2BP, UK.

\section{Autistic genius?}

\section{Autism and Creativity: Is There a Link between Autism in Men and Exceptional Ability?}

by Michael Fitzgerald

Brunner-Routledge: 2003. 304 pp.

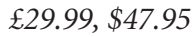

\section{Autism: Mind and Brain}

edited by Uta Frith and Elisabeth Hill Oxford University Press: 2003. 298 pp.

$£ 70, \$ 110$ ( $h b k$ ); $£ 29.95, \$ 49.50$ (pbk)

\section{Allan Snyder}

We tend to see only the whole - it takes insights from abnormal minds to appreciate how the brain assembles the parts. So could studies of autism reveal insights into creativity? It seems unlikely. The classical portrait of autism includes low intelligence, significant learning disabilities, memory by rote, literalness and a rigid insistence on sameness. Even autistic savants, known for their extraordinary mental feats, are not creative. Rather, they adopt a form of mimicry, probably due to privileged access to non-conscious processes. Beate Hermelin, an expert on autism, says that no savant will discover a new mathematical theorem, initiate a novel stylistic movement, or render a revealing interpretation of a Beethoven piano sonata.

But as these two superb new books demonstrate, our view of autism is radically transforming. It now embraces the classical picture of severe mental impairment at one end of the spectrum and possibly Nobelprizewinning creative genius at the other. Both extremes have in common certain core autistic features, such as preoccupation with detail, obsessional interests and difficulties in understanding another person's perspective.

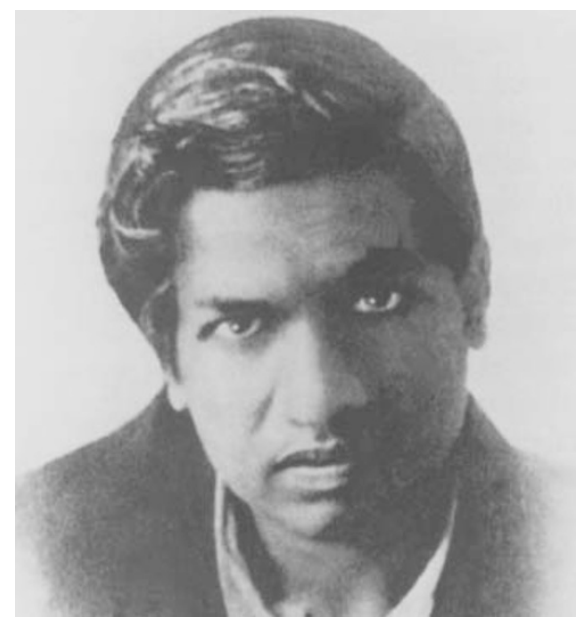

Did autism help shape the thinking of Indian mathematician Srinivasa Ramanujan?

Michael Fitzgerald, author of Autism and Creativity, says that some aspects of highfunctioning autism and Asperger's syndrome enhance creativity. Because these developmental disorders are mainly genetic in origin and largely affect men, he believes that creativity in a broader sense is predominantly the result of genetic rather than environmental factors: "The view that geniuses began their lives made from the same material as the rest of us ... is false." He then engages in retrospective diagnosis to support such claims, declaring that several individuals "with creativity of genius proportions" fit the high end of the autistic spectrum. These include Isaac Newton, the philosopher Ludwig Wittgenstein, mathematician Srinivasa Ramanujan, Lewis Carroll, the poet W. B. Yeats, and politicians Keith Joseph and Eamon de Valera. Apparently Hitler too had autistic traits.

Fitzgerald's thesis is not new. Hans Asperger spoke of "autistic intelligence" as being intelligence of "true creativity", adding "it seems that for success in science or art a dash of autism is essential." Oliver Sacks suggested that Wittgenstein had autistic traits. So too did Einstein, van Gogh and possibly Bill Gates, according to Temple Grandin, who is herself autistic. Asperger even noted that the autistic mind is an extreme variant of male intelligence. Despite these earlier revelations, Fitzgerald's tantalizing book is a must read, as are Simon Baron-Cohen's brilliant contributions to this area, such as The Essential Difference (Perseus, 2003).

The fact that genius can fall within the autistic spectrum challenges our deepest notions of creativity. Are there two different routes to creativity: normal and autistic? The normal mind is good at recognizing the gist of something but poor at recalling details. This, I believe, is because the brain forms concepts or mental models that encapsulate the familiar. Concepts impart automatic judgements and confer intuition, but hide details from conscious awareness. As a result, we see the whole but not the parts. In contrast, the 


\section{The German Hygiene Museum in Dresden is reopening its doors.}

\section{Alison Abbott}

Last year an undetonated Second World War bomb was discovered near the German Hygiene Museum in Dresden. It was a reminder, if any were needed, of the dramatic history of the museum, which this week reopens its valuable permanent collection, 14 years after German reunification.

Most of the bombs did their job in 1945, however -the museum was $80 \%$ destroyed. Gone, too, was the Nazi ideology that had perverted its original, progressive, aim: enlightened health education.

By the start of the twentieth century, the infectious basis of common diseases was understood and, in the absence of antibiotics, the emphasis was on avoiding infection. Interest was high some 30 nations took part in the First International Hygiene Exhibition held in Dresden in 1911.

The exhibition, which attracted more than five million visitors, was so successful that a permanent German Hygiene Museum was founded in Dresden the following year, moving into its permanent home - an imposing building in the Bauhaus tradition - in 1930.

Workshops sprang up to manufacture anatomical models and teaching aids of ever greater ingenuity and no small artistic value. These included moulages, or wax models of healthy or diseased body parts, transparent human organs produced by a new method developed by the Leipzig doctor Werner Spalteholz, and didactic wall charts. Most famously, Franz Tschakert prepared plastic-coated anatomical statues known as Gläserne Menschen (transparent people), complete with real or artificial skeleton, wax organs and thousands of metres of painted wire representing blood vessels and nerves.

The first Transparent Man was unveiled at the opening of the museum's new building in 1930 . He stood on a plinth in an apse-like recess, a setting that no doubt added to the spiritual atmosphere he exuded with his exultantly outstretched arms.

autistic mind is literal and sees more of the parts than the whole. An impairment in the process of concept formation denies intuition, but allows access to details that are normally non-conscious. Consequently, the autistic mind must build logically from the parts to what is intuitive to a normal mind.

The autistic mind seems to be suited to working algorithmically within a closed system of specified rules. In contrast, the normal mind can make unexpected connections between seemingly disparate systems often by breaking the rules of each when taken in isolation, but not as an ensemble. In other words, a normal mind invents entire new systems rather than finding novelty within a previously prescribed space. Is it possible to have the best of both worlds? Could certain psychopathologies inadver-

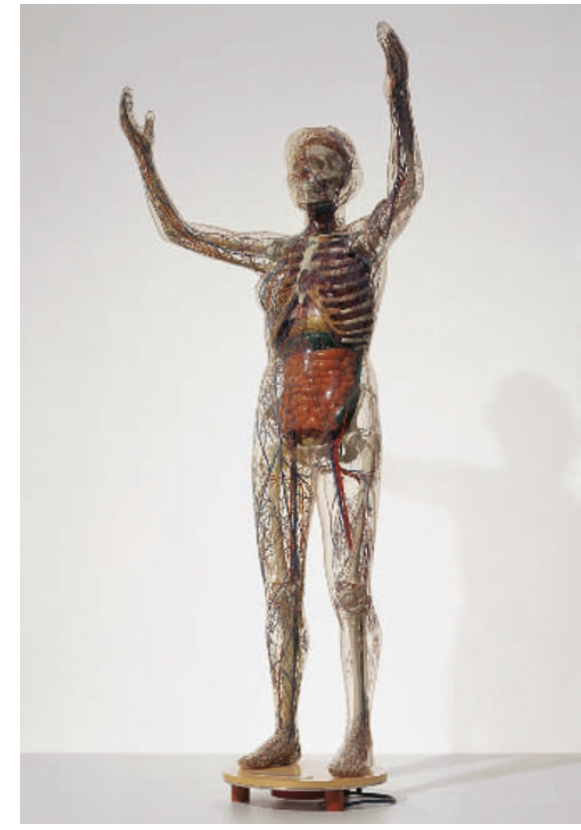

It's clear to see: the Transparent Woman reveals her internal organs at the Hygiene Museum.

But three years later the atmosphere changed. Extending the general enthusiasm for hygiene to racial hygiene and eugenics, Nazi Germany subverted the museum for propaganda. In 1933 the Nazis also sacked the museum's Jewish employees and destroyed the frescoes in its restaurant painted by expressionist Otto Dix, as they considered him a degenerate artist.

The museum somehow maintained its professional reputation to the extent that its rebuilding became a priority for the Russian occupying army shortly after the bombing, and was completed within a year. The museum became a flagship of the new Communist state of East Germany, where it continued its official mandate to educate the public

tently plunge someone into a temporary state of autism, allowing them to see the parts normally denied to conscious awareness?

To gain deeper perspective on such issues requires information from diverse research. The second book under review, edited by Uta Frith and Elisabeth Hill, gives a valuable update in 13 insightful chapters, written by authorities on the subject. I especially enjoyed the editors' two chapters and those by the groups of Baron-Cohen, Happé and Schultz. Although tilted to the specialist, this excellent book portrays a panoramic view of autism. It is loaded with all kinds of goodies: autism is no longer a rare disease; it can be associated with congenital blindness; people with autism have difficulty recognizing faces; they show a strong desire to systematize; and on average their brains are larger about health issues. It spoke to the wider world albeit with forked tongue - of East Germany's strengths in technology and education. Despite shortages of materials, the manufacture, sale and export of its anatomical models grew. It produced the first black anatomical models for export to Africa, and developed special wax for moulages exported to hot climates. It sold more than a hundred transparent men and women, extending its repertoire to transparent cows and horses.

But reunification put an end to the museum's official purpose - West Germany already had a government office for health education.

The permanent exhibition is part of the museum's development of a fresh identity. The first of the four new exhibition rooms is dedicated to the Transparent Man, which remains a metaphor for enlightenment and transparency about the past, as well as allowing us to see tissues and organs. Instrumentation on show includes a first-generation $\mathrm{X}$-ray machine. And there is a range of historical anatomical models, including the first Transparent Woman and a more recent model whose organs light up when buttons are pressed. The other rooms feature life and death, eating and drinking, and sexuality. Three additional rooms, dedicated to movement and the cardiovascular system, neuroscience, and skin, will open next year.

The museum's curators have eschewed recent trends towards amusement-park styles of presentation. This is a place to learn, and the museum's important collection is central. Unobtrusive computer terminals provide further information, which can be e-mailed to visitors' home computers. The displays' strong, simple and light design — the ultimate in German chic - creates an effect that is modern and learned, calm and uncluttered, despite the wealth of objects. Its elegance is a tribute to its early, avant-garde history.

Alison Abbott is Nature's senior European correspondent.

and heavier than normal brains from around the age of 2-4 years (but probably not as adults). Movement disturbances may play a role in autism - a reduction in facial expressions may reflect problems with the underlying social brain network.

We are told that there is still no unifying theory of autism. But I suggest that a failure in the process of concept formation and its associated top-down inhibition of the parts that make up the whole may offer a mechanism that could unite the current descriptive theories. Concepts order the world internally. Without them, order must be imposed externally, hence the setting up of rigid routines. Allan Snyder is director of the Centre for the Mind, a joint venture of the Australian National University, Canberra, ACT 0200, and the University of Sydney, Sydney, New South Wales 2006, Australia. 